\title{
PIPER SARMENTOSUM INCREASES NITRIC OXIDE PRODUCTION IN OXIDATIVE STRESS: A STUDY ON HUMAN UMBILICAL VEIN ENDOTHELIAL CELLS
}

\author{
Azizah Ugusman, Zaiton Zakaria, Chua Kien Hui, Nor Anita Megat Mohd Nordin
}

doi: $10.1590 / \mathbf{S 1 8 0 7 - 5 9 3 2 2 0 1 0 0 0 0 7 0 0 0 1 0}$

Ugusman A, Zakaria Z, Hui CK, Megat Mohd Nordin NA. Piper sarmentosum increases nitric oxide production in oxidative stress: a study on human umbilical vein endothelial cells. Clinics. 2010;65(7):709-14.

OBJECTIVE: Nitric oxide produced by endothelial nitric oxide synthase (eNOS) possesses multiple anti-atherosclerotic properties. Hence, enhanced expression of eNOS and increased Nitric oxide levels may protect against the development of atherosclerosis. Piper sarmentosum is a tropical plant with antioxidant and anti-inflammatory activities. This study aimed to investigate the effects of Piper sarmentosum on the eNOS and Nitric oxide pathway in cultured human umbilical vein endothelial cells (HUVECs).

METHODS: HUVECs were divided into four groups: control, treatment with $180 \mu \mathrm{M}$ hydrogen peroxide $\left(\mathrm{H}_{2} \mathrm{O}_{2}\right)$, treatment with $150 \mu \mathrm{g} / \mathrm{mL}$ aqueous extract of Piper sarmentosum, and concomitant treatment with aqueous extract of PS and $\mathrm{H}_{2} \mathrm{O}_{2}$ for 24 hours. Subsequently, HUVECs were harvested and eNOS mRNA expression was determined using qPCR. The eNOS protein level was measured using ELISA, and the eNOS activity and Nitric oxide level were determined by the Griess reaction.

RESULTS: Human umbilical vein endothelial cells treated with aqueous extract of Piper sarmentosum showed a marked induction of Nitric oxide. Treatment with PS also resulted in increased eNOS mRNA expression, eNOS protein level and eNOS activity in HUVECs.

CONCLUSION: Aqueous extract of Piper sarmentosum may improve endothelial function by promoting NO production in HUVECs.

KEYWORDS: Piper sarmentosum, Nitric oxide, Endothelial nitric oxide synthase, Oxidative stress, Human umbilical vein endothelial cells.

\section{INTRODUCTION}

Nitric oxide (NO) in the endothelium is synthesized by endothelial nitric oxide synthase (eNOS) via the conversion of L-arginine to L-citrulline. The reaction requires the presence of the following cofactors: nicotinamide adenine dinucleotide phosphate (NADPH), calcium/ calmodulin (CaM), flavin adenine dinucleotide (FAD), flavin mononucleotide $(\mathrm{FMN})$ and tetrahydrobiopterin $(\mathrm{BH}))^{1,2}$

Nitric oxide has been recognized as a major antiatherogenic factor because of its vasoprotective activity. ${ }^{3}$ Nitric oxide induces vasorelaxation by activating soluble guanylate cyclase; thus, NO plays an important role in

Department of Physiology, Universiti Kebangsaan, Malaysia Medical Center - Kuala Lumpur/Malaysia.

Email: zaitonukm@gmail.com

Received for publication on March 05, 2010

First review completed on March 22, 2010

Accepted for publication on April 12, 2010 regulating the vascular tone. Nitric oxide has also been shown to inhibit oxidation of low-density lipoprotein (LDL) and antagonize platelet aggregation by inhibiting platelet activation. ${ }^{3}$ Moreover, NO inhibits nuclear factor- $\mathrm{\kappa B}$ dependent expression of adhesion molecules that mediate recruitment of leukocytes to the endothelium in the early phase of atherosclerosis. Nitric oxide has been shown to suppress abnormal proliferation of vascular smooth muscle cells, which contribute to the narrowing of atherosclerotic vessel walls. ${ }^{3}$ Based on these anti-atherosclerotic properties, the enhancement of endothelial NO production may play an important role in the prophylaxis or treatment of cardiovascular diseases. ${ }^{4}$

Oxidative stress plays an important role in the pathogenesis of atherosclerosis and cardiovascular diseases by promoting endothelial dysfunction, inflammation and lipid/lipoprotein peroxidation as well as by reducing NO bioavailability. ${ }^{5}$ Loss of normal NO production from the endothelium is a cardinal feature of endothelial 
dysfunction. ${ }^{6}$ Endothelial dysfunction is characterized by a reduction in the bioavailability of $\mathrm{NO}$, which is followed by increased levels of endothelium-derived vasoconstrictors such as endothelin-1. ${ }^{7}$ This imbalance leads to impairment of endothelium-derived relaxation (EDR). Arteries may thereby be predisposed to increased vascular tone and vasospasm. Impairment of EDR was found in atherosclerotic vessels even before vascular structural changes had ensued. ${ }^{8}$

Piper sarmentosum (PS) is a creeping terrestrial herbaceous plant that belongs to the Piperaceae family. It is commonly found in the tropical and subtropical regions of the world, such as the Asian region. The leaves and roots of this plant have been used for the treatment of toothache, fungoid dermatitis on the feet, cough, asthma and pleurisy. ${ }^{9}$ Chloroform extracts of Piper sarmentosum have the ability to act as an anti-malarial agent against Plasmodium falciparum and Plasmodium berghei..$^{10}$ The aqueous extract of the entire plant has been reported to have hypoglycemic effects in experimental rats. ${ }^{11}$ Furthermore, the ethanolic extract of PS exerted anti-carcinogenic effects through an intrinsic apoptosis pathway in HepG2 cells. ${ }^{13}$ The aqueous extract of PS also exhibited anti-nociceptive and anti-inflammatory activities in vivo. ${ }^{14}$ Recent research has demonstrated that various extracts prepared from PS leaves have antioxidant and anti-tuberculous activities. ${ }^{12}$ To date, however, there is no direct evidence linking PS to the eNOS system. Based on the properties of PS extracts mentioned above, the present study was designed to investigate the effects of PS on the eNOS system and NO synthesis in human umbilical vein endothelial cells (HUVECs). The results of the present study may help in the prevention and treatment of atherosclerosis, which is linked to various cardiovascular diseases.

\section{MATERIALS AND METHODS}

\section{Preparation of aqueous extract of Piper sarmentosum}

Leaves of PS were collected in Sungai Buloh, Malaysia, and identified by a plant taxonomist from the Forest Research Institute of Malaysia (voucher specimen: FRI 45870). The leaves were washed with tap water, cut into small pieces, sun-dried and ground into powder form. A $10 \%$ aqueous extract of Piper sarmentosum (AEPS) was prepared by soaking $100 \mathrm{~g}$ of the powdered leaves in 900 $\mathrm{mL}$ of purified water followed by incubation in a high-speed mixer at $80{ }^{\circ} \mathrm{C}$ for 3 hours. After cooling, the extract was filtered using mesh and further concentrated. The aqueous extract was then freeze-dried to powdered form and kept at $4{ }^{\circ} \mathrm{C}$ until the experiments.

\section{Cell culture and treatment protocols}

Human umbilical vein endothelial cells were obtained from umbilical cord veins using $0.1 \%$ type I collagenase (Gibco-Invitrogen Corp., Grand Island, N.Y.) digestion. Cells were grown in medium-200 (Cascade Biologics, USA) supplemented with LSGS (low-serum growth supplement; Cascade Biologics, USA) at $37{ }^{\circ} \mathrm{C}$ in a humidified atmosphere of $5 \% \mathrm{CO}_{2}$ and $95 \%$ air. Human umbilical vein endothelial cells were identified by the typical endothelial cell cobblestone morphology and positive expression of vonWillebrand factor and CD31 in immunocytochemistry. The culture medium was changed every other day until the cells reached confluence. Human umbilical vein endothelial cells from passage 3 at $80 \%$ confluency were used for the experiments. The cells were divided into four groups: control (CTRL), treatment with $180 \mu \mathrm{M}$ hydrogen peroxide $\left(\mathrm{H}_{2} \mathrm{O}_{2}\right)$ to induce oxidative stress; treatment with $150 \mu \mathrm{g} / \mathrm{mL}$ AEPS, and concomitant treatment with $150 \mu \mathrm{g} / \mathrm{mL}$ AEPS and 180 $\mu \mathrm{M} \mathrm{H}_{2} \mathrm{O}_{2}$. All treatments were given for 24 hours.

\section{Quantitative reverse transcription polymerase chain re- action (qPCR) for analysis of eNOS mRNA expression}

After treatment for 24 hours, total ribonucleic acid (RNA) from HUVECs was extracted using TRI Reagent (Molecular Research Center, Cincinnati, USA) according to a previously published protocol. ${ }^{15}$ Polyacryl carrier (Molecular Research Center, Cincinnati, USA) was added to precipitate the total RNA. The extracted RNA pellet was then washed with $75 \%$ ethanol and dried prior to being dissolving in RNase- and DNase-free water (Invitrogen, Carlsbad, USA). The extracted total RNA was assessed for its purity and quantity using a Nanodrop ND-100 spectrophotometer (Wilmington DE, USA) and stored at $-80{ }^{\circ} \mathrm{C}$. Complimentary DNA (cDNA) was synthesized using SuperScript III First-Strand Synthesis SuperMix (Invitrogen, Carlsbad, USA). A total reaction volume of 20 $\mu \mathrm{l}$, which consisted of $10 \mu \mathrm{l}$ of $2 \mathrm{X}$ RT Reaction Mix, $2 \mu \mathrm{l}$ of RT enzyme, $5 \mu$ of total RNA and $3 \mu$ of DEPC-treated water, was incubated at $25{ }^{\circ} \mathrm{C}$ for 10 minutes for primer annealing. The reaction was then incubated at $50{ }^{\circ} \mathrm{C}$ for 30 minutes for reverse transcription. Finally, the reaction was terminated at $85{ }^{\circ} \mathrm{C}$ for 5 minutes and chilled on ice for 1 minute, after which $1 \mu \mathrm{l}$ of $E$. coli RNase $\mathrm{H}$ was added to the mixture. The cDNA was further incubated at $37{ }^{\circ} \mathrm{C}$ for 20 minutes and stored at $-20{ }^{\circ} \mathrm{C}$. Subsequently, qPCR was carried out to determine the mRNA expression level of eNOS. Glyceraldehyde-3-phosphate dehydrogenase $(\mathrm{GAPDH})$ was used as the reference gene. Primer 3 software (http://frodo:wi.mit.edu/cgi-bin/primer3/primer3- 
www.cgi) was used to design the primers from the NIH GenBank database. The following sequences were used as primers for eNOS [GenBank: NM_000603] and GAPDH [GenBank: BC020308]: CTCCAGCCCCGGTACTACTC (forward) and TTAGCCACGTGGAGCAGACT (reverse), and TCCCTGAGCTGAACGGGAAG (forward) and GGAGGAGTGGGTGTCGCTGT (reverse), respectively. The qPCR reaction was performed in a BioRad iCycler (Bio-Rad, USA) with $1 \mu \mathrm{l}$ of cDNA, $5 \mu \mathrm{M}$ of each forward and reverse primer and $12.5 \mu \mathrm{l}$ of IQ SYBR Green Supermix (Bio-Rad, USA). The reaction profile consisted of 40 cycles using the following parameters: 95 C (10 seconds) and $61 \mathrm{C}$ (30 seconds). The reaction kinetics of each primer set and protocol were verified with the melting profile, and product size was further confirmed with $2 \%$ agarose gel electrophoresis stained with ethidium bromide (Sigma, St Louis, USA). The threshold cycle $\left(\mathrm{C}_{\mathrm{T}}\right)$ value was determined, and the relative mRNA expression of eNOS was calculated with the following equation: $2^{\Delta \Delta C \mathrm{~T}}$, where $\Delta \Delta \mathrm{C}_{\mathrm{T}}=$ $\mathrm{C}_{\mathrm{T}} \mathrm{GAPDH}-\mathrm{C}_{\mathrm{T}}$ eNOS.

\section{Enzyme-linked immunosorbent assay (ELISA) for eNOS protein analyses}

The eNOS protein level of the cultured HUVECs was determined using the Quantikine human eNOS ELISA kit (R\&D Systems). Human umbilical vein endothelial cells were washed twice with phosphate-buffered saline (PBS), manually scraped from the culture flask and lysed with $400 \mu \mathrm{L}$ of lysis buffer. The assay was performed using $100 \mu \mathrm{L}$ of the cell lysate. The cell lysate was pipetted into the 96-well plate so that any eNOS that was present would be bound to the immobilized antibody in the plate. After washing away any unbound substances, eNOS conjugate was added to the wells. This was followed by the addition of substrate solution and stop solution. The optical density of each well was determined at $450 \mathrm{~nm}$ using an ELISA microplate reader.

\section{Determination of eNOS Activity}

The eNOS activity was determined using a commercially available kit (Nitric Oxide Synthase Colorimetric Assay, Calbiochem, USA). The principle of this assay was based on the measurement of nitrite produced by eNOS in the sample in a timed reaction. Human umbilical vein endothelial cells were scraped from the culture flask, homogenized in PBS and centrifuged at 10,000 $\mathrm{g}$ for 20 minutes. Then, the cell lysate in the supernatant solution was filtered through a $0.45 \mu \mathrm{m}$ filter prior to ultracentrifugation at $100,000 \mathrm{~g}$ for 15 minutes. A total of $40 \mu \mathrm{L}$ of the cell lysate was diluted with $20 \mu \mathrm{L}$ of assay buffer. Next, the samples were mixed with NADPH, nitrate reductase, cofactor preparation solution and lactate dehydrogenase (LDH). Total nitrite was measured at $540 \mathrm{~nm}$ with Griess reagents (sulfanilamide and naphthalene-ethylene diamine dihydrochloride). The concentration of nitrite in the sample was calculated using a standard curve. The eNOS activity was expressed as nmol of nitrite/min per $\mathrm{mL}$ of sample.

\section{Determination of endothelial nitric oxide production}

Production of NO by HUVECs was measured via its stable oxidation product, nitrite, using a commercial kit (BIOXYTECH Nitric Oxide Colorimetric Assay, OXIS Research, USA). Briefly, $50 \mu \mathrm{L}$ of the culture medium was diluted with $35 \mu \mathrm{L}$ of assay buffer and mixed with $10 \mu \mathrm{L}$ of nitrate reductase and $10 \mu \mathrm{L}$ NADH. After 20 minutes of incubation to convert nitrate to nitrite, total nitrite was measured at $540 \mathrm{~nm}$ with Griess reagents (sulfanilamide and naphthalene-ethylene diamine dihydrochloride).

\section{Statistical analysis}

Data were tested for normality using the KolmogorovSmirnov test, and all variables were normally distributed. Data were expressed as mean \pm SEM. Statistical analyses between two groups were performed with Student's paired $t$-test using SPSS version 16.0 software. Values of $\mathrm{p}<0.05$ were considered statistically significant.

\section{RESULTS}

\section{eNOS mRNA expression in HUVECs}

Treatment of HUVECs with AEPS significantly enhanced eNOS mRNA expression by 2.3 -fold (4.405 \pm $\left.0.892 \times 10^{-3}\right)$ compared with the control group (1.915 \pm $0.428 \times 10^{-3}$ ) (Figure 1). In the oxidative stress-induced group, HUVECs treated with $\mathrm{H}_{2} \mathrm{O}_{2}$ also showed a significantly higher (2.2-fold) level of eNOS mRNA expression $\left(4.280 \pm 0.760 \times 10^{-3}\right)$ compared with the control group. However, concomitant treatment of HUVECs with both AEPS and $\mathrm{H}_{2} \mathrm{O}_{2}$ did not result in a significant increase in eNOS mRNA expression $\left(2.95 \pm 0.697 \times 10^{-3}\right)$ compared to the control group.

\section{eNOS protein level in HUVECs}

The aqueous extract of PS significantly increased the eNOS protein level by 1.4 -fold $\left(1.706 \pm 0.154 \times 10^{3} \mathrm{pg} / \mathrm{mL}\right)$ compared with the control group $\left(1.235 \pm 0.170 \times 10^{3} \mathrm{pg} /\right.$ 


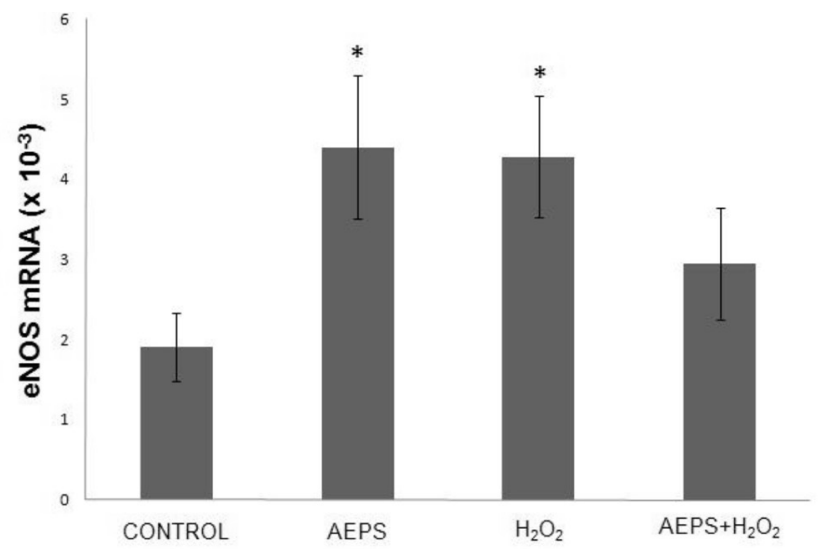

Figure 1 - eNOS mRNA expression in HUVECs.

$\mathrm{mL}$ ) (Figure 2), which was consistent with the changes in eNOS mRNA. Treatment of HUVECs with $\mathrm{H}_{2} \mathrm{O}_{2}$ alone also resulted in a significantly higher (1.3-fold) level of eNOS protein $\left(1.669 \pm 0.137 \times 10^{3} \mathrm{pg} / \mathrm{mL}\right)$ compared with the control group. Concomitant treatment of HUVECs with both AEPS and $\mathrm{H}_{2} \mathrm{O}_{2}$ did not result in a significant increase in eNOS protein level $\left(1.549 \pm 0.096 \times 10^{3} \mathrm{pg} / \mathrm{mL}\right)$ compared with the control group.

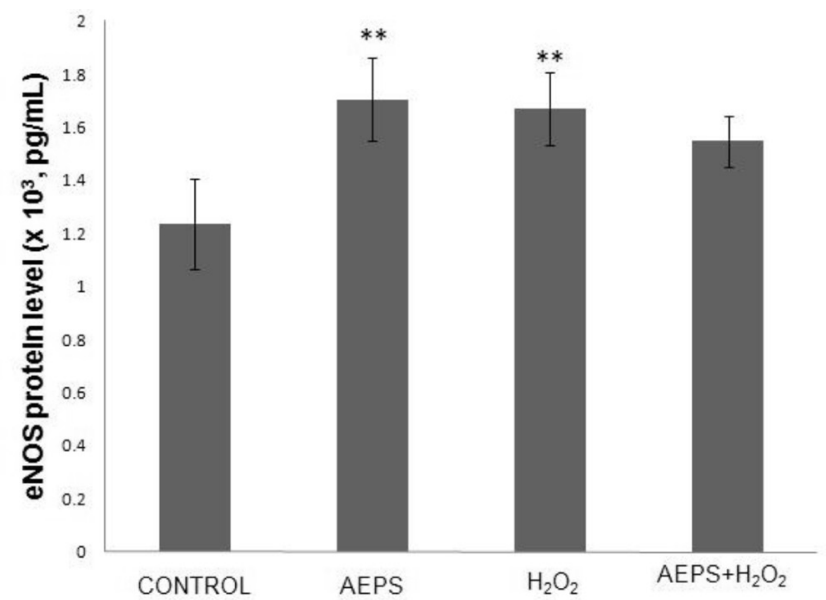

Figure 2 - eNOS protein level in HUVECs.

\section{eNOS activity in HUVECs}

Treatment of HUVECs with AEPS significantly promoted eNOS enzyme activity $\left(5.237 \pm 0.55 \times 10^{-2} \mathrm{nmoles} /\right.$ $\mathrm{mL} / \mathrm{min})$ compared with the control group $(4.393 \pm 0.74$ x $10^{-2} \mathrm{nmoles} / \mathrm{mL} / \mathrm{min}$ ) (Figure 3). In the oxidative stressinduced group, HUVECs treated with $\mathrm{H}_{2} \mathrm{O}_{2}$ also showed a significantly higher level of eNOS enzyme activity (5.863 $\pm 0.57 \times 10^{-2} \mathrm{nmoles} / \mathrm{mL} / \mathrm{min}$ ) compared with the control group. Concomitant treatment of HUVECs with both AEPS and $\mathrm{H}_{2} \mathrm{O}_{2}$ did not result in a significant increase in eNOS

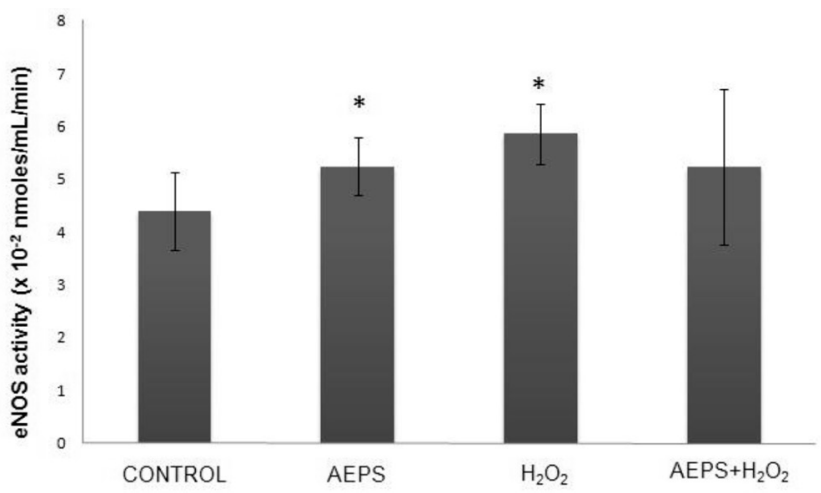

Figure 3 - eNOS activity in HUVECs.

enzyme activity $\left(5.228 \pm 1.473 \times 10^{-2} \mathrm{nmoles} / \mathrm{mL} / \mathrm{min}\right)$ compared with the control group.

\section{Nitric oxide production in HUVECs}

The aqueous extract of PS significantly promoted NO production in HUVECs by 6.3 -fold $(15.446 \pm 3.879 \mu \mathrm{M})$ compared with the control group $(2.454 \pm 0.799 \mu \mathrm{M})$ (Figure 4). In the oxidative stress-induced group, HUVECs treated with $\mathrm{H}_{2} \mathrm{O}_{2}$ also showed a significantly higher (1.7fold increase) level of NO production $(4.175 \pm 0.966 \mu \mathrm{M})$ compared with the control group. The greatest increase in NO production $(17.536 \pm 3.55 \mu \mathrm{M})$ was observed in HUVECs treated with both AEPS and $\mathrm{H}_{2} \mathrm{O}_{2}$; the level of NO production was significantly higher than that in the control and $\mathrm{H}_{2} \mathrm{O}_{2}$ groups.

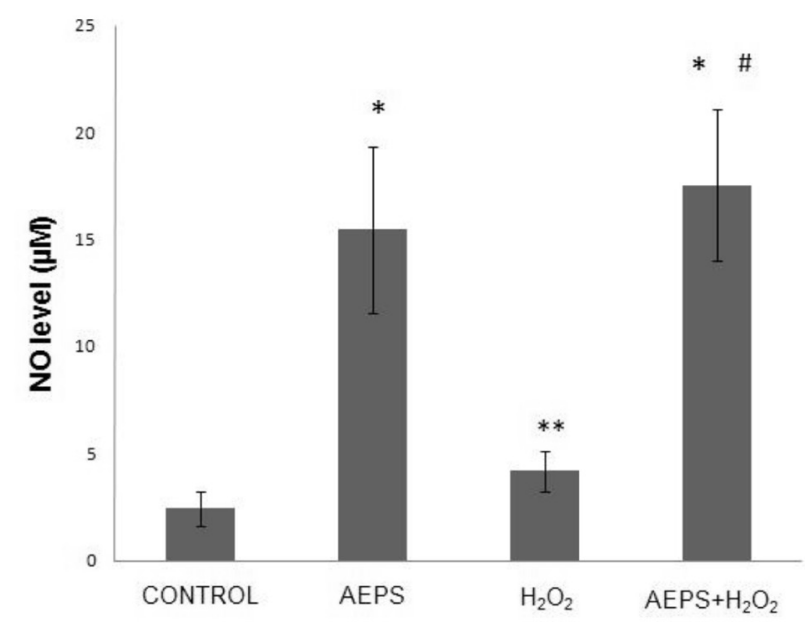

Figure 4 - Nitric oxide production in HUVECs.

\section{DISCUSSION}

Oxidative stress can contribute to the development and progression of atherosclerosis by promoting endothelial dysfunction, inflammation and lipid peroxidation, as well 
as by reducing NO bioavailability. ${ }^{16}$ Based on the results of a previous study, we used $180 \mu \mathrm{M} \mathrm{H}_{2} \mathrm{O}_{2}$ to induce oxidative stress in HUVECs. ${ }^{17}$ This concentration of $\mathrm{H}_{2} \mathrm{O}_{2}$ increased eNOS mRNA expression, eNOS protein level and eNOS activity (Figure 1, 2, 3). In another study, incubation of bovine aortic endothelial cells with $150 \mu \mathrm{M} \mathrm{H}_{2} \mathrm{O}_{2}$ for 24 hours also caused an increase in eNOS mRNA, eNOS protein and eNOS enzyme activity. ${ }^{18}$

The NO level was higher in the $\mathrm{H}_{2} \mathrm{O}_{2}$-treated group compared to the control group. This may have been due to induction of $\mathrm{NO}$ production by $\mathrm{H}_{2} \mathrm{O}_{2}$ as part of the selfprotective mechanism of the cells. The dose of $\mathrm{H}_{2} \mathrm{O}_{2}$ used in this study was not lethal to HUVECs; therefore, the cells were still able to increase their endogenous NO production after an $\mathrm{H}_{2} \mathrm{O}_{2}$ challenge. However, $\mathrm{H}_{2} \mathrm{O}_{2}$ also caused oxidative destruction of the synthesized $\mathrm{NO}$, which explains why the increase in $\mathrm{NO}$ in the $\mathrm{H}_{2} \mathrm{O}_{2}$ treated group was not as high as in the other groups (i.e., the AEPS and the combined AEPS and $\mathrm{H}_{2} \mathrm{O}_{2}$ groups) (Figure 4).

In this study, the responses to $\mathrm{H}_{2} \mathrm{O}_{2}$ are in agreement with earlier reports. ${ }^{5}$ The expression of eNOS in endothelial cells is regulated by NO through a negative feedback mechanism at both the transcriptional and translational levels. Hydrogen peroxide-derived upregulation of eNOS was mediated by diminished $\mathrm{NO}$ availability and a consequent reduction in the negative feedback regulatory action of NO on eNOS expression. This represents a compensatory protective mechanism of the cells to a reduction in $\mathrm{NO}$ availability induced by acute exposure to $\mathrm{H}_{2} \mathrm{O}_{2}{ }^{5}$ Hydrogen peroxide has been shown to increase eNOS activity by inducing changes in the phosphorylation status of the enzyme. This response represents an attempt by the endothelial cells to maintain NO bioactivity under conditions of increased oxidative stress. ${ }^{19}$

It is well recognized that NO produced by eNOS plays a protective role against the development of atherosclerosis and endothelial dysfuntion. ${ }^{20,21}$ The results of this study show that AEPS $(150 \mu \mathrm{g} / \mathrm{mL})$ significantly increased NO production in HUVECs (Figure 4). AEPS also induced increases in eNOS mRNA, protein and activity (Figure 1, $2,3)$. The higher amount of eNOS protein caused a higher level of eNOS activity. This resulted in an increase in NO production by HUVECs. The results of the present study suggest that AEPS may improve endothelial function by augmenting NO production in human endothelial cells. Thus, AEPS could reduce the risk of atherosclerosis.

Antioxidants are known to enhance the biological actions of NO by protecting $\mathrm{NO}$ against oxidative destruction by reactive oxygen species. ${ }^{21}$ AEPS has been shown to exhibit antioxidant properties. ${ }^{12}$ Thus, AEPS can directly protect $\mathrm{NO}$ from oxidative destruction by $\mathrm{H}_{2} \mathrm{O}_{2}$ (Figure 4). The aqueous extract of PS also promoted NO production from HUVECs by increasing eNOS protein synthesis and enzyme activity (Figure 2,3). Therefore, both protection of NO from oxidative destruction and enhancement of eNOS activity by AEPS caused an increase in NO level.

We observed the largest increase in NO production in the group that received AEPS and $\mathrm{H}_{2} \mathrm{O}_{2}$. Since AEPS can directly protect $\mathrm{NO}$ from oxidative destruction by $\mathrm{H}_{2} \mathrm{O}_{2}, \mathrm{NO}$ is available in the cells at a higher level. A higher level of NO in the cells reduced the mRNA expression and protein synthesis of eNOS via a negative feedback mechanism. ${ }^{5}$

Previous phytochemical screening of PS revealed the presence of a variety of natural products, such as amides, polyphenols and flavonoids. ${ }^{12}$ Myricetin, apigenin and quercetin are examples of flavonoids identified in PS leaves. ${ }^{22}$ Quercetin improved endothelial dysfunction by increasing NO synthesis in HUVECs. The increase in NO synthesis was attributed to an enhancement of eNOS activity via increased calcium concentration. ${ }^{23}$ Quercetin has also been reported to exert endothelium-dependent vasodilatation of porcine aortic rings. ${ }^{24}$ Therefore, in the present study, the flavonoids appear to be the active constituents of AEPS responsible for enhancing NO production in HUVECs.

\section{STUDY LIMITATIONS}

This experiment was an in vitro study that investigated some fundamental biomolecular and cellular activities. The data suggest that AEPS could reduce the risk of atherosclerosis by increasing the bioavailability of NO to defend against oxidative stress. A clinical placebocontrolled study may be needed before employing AEPS as an effective supplement. If this study were performed in a clinical setting, we could attempt to determine dosage, pharmacokinetics and pharmacodynamics of AEPS.

\section{CONCLUSION}

In summary, the present study demonstrated that AEPS increased eNOS mRNA expression, protein synthesis, eNOS activity and NO production that could protect HUVECs from from oxidative stress. Based on the vasoprotective and anti-atherosclerotic effects of endothelial NO, AEPS has the ability to reduce the risk of atherosclerosis. Further studies are needed to corroborate these findings. 


\section{REFERENCES}

1. Govers R, Rabelink T. Cellular regulation of endothelial nitric oxide synthase. Am Physiological Soc. 2001;280:193-206.

2. Förstermann U. Janus-faced role of endothelial NO synthase in vascular disease: uncoupling of oxygen reduction from NO synthesis and its pharmacological reversal. J Biol Chem. 2006;387:1521-33.

3. Naseem K. The role of nitric oxide in cardiovascular diseases. Mol Aspects Med. 2005;26:33-65.

4. Ignarro L, Napoli C. Novel features of nitric oxide, endothelial nitric oxide synthase, and atherosclerosis. Current Atherosclero Reps. 2004;6:281-7.

5. Zhen J, Lu H, Wang X, Vaziri N, Zhou X. Upregulation of endothelial and inducible nitric oxide synthase expression by reactive oxygen species. Amer J Hypertension. 2008;21:28-34.

6. Park S, Jung W, Moon S, Ko C, Cho K, Kim Y, et al. Chunghyuldan activates NOS mRNA expression and suppresses VCAM-1 mRNA expression in human endothelial cells. Can J Physiol Pharmacol. 2005;83:1101-8.

7. Bonetti P, Lerman L, Lerman A. Endothelial Dysfunction A Marker of Atherosclerotic Risk. Am Heart Assoc. 2003;23:168-75.

8. Kawashima S. Malfunction of Vascular Control in Lifestyle-Related Diseases: Endothelial Nitric Oxide (NO) Synthase/NO System in Atherosclerosis. J Pharmacol Sci. 2004;96:411-9.

9. Rukachaisirikul T, Siriwattanakit P, Sukcharoenphol K, Wongvein C, Ruttanaweang P, Wongwattanavuch P, et al. Chemical constituents and bioactivity of Piper sarmentosum. J Ethnopharmacol. 2004;93:173-6.

10. Najib Nik A Rahman N, Furuta T, Kojima S, Takane K, Ali Mohd M. Antimalarial activity of extracts of Malaysian medicinal plants. J Ethnopharmacol. 1999;64:249-54.

11. Peungvicha P, Thirawarapan S, Temsiririrkkul R, Watanabe H, Kumar Prasain J, Kadota S. Hypoglycemic effect of the water extract of Piper sarmentosum in rats. J Ethnopharmacol. 1998;60:27-32.

12. Hussain K, Ismail Z, Sadikun A, Ibrahim P. Antioxidant, anti-TB activities, phenolic and amide contents of standardised extracts of Piper sarmentosum Roxb. Nat Pro Res. 2009;23:238-49.

13. Hisham Z, Haryani W, Zaidah Z, Fauzi S, Sahidan S, Rohaya M. Intrinsic anticarcinogenic effects of Piper sarmentosum ethanolic extract on a human hepatoma cell line. Cancer Cell Int. 2009;9:6.
14. Zakaria Z, Patahuddin H, Mohamad A, Israf D, Sulaiman M. In vivo anti-nociceptive and anti-inflammatory activities of the aqueous extract of the leaves of Piper sarmentosum. J Ethnopharmacol. 2010;128:42-8.

15. Chua K, Aminuddin B, Fuzina N, Ruszymah B. Insulin-transferrinselenium prevent human chondrocyte dedifferentiation and promote the formation of high quality tissue engineered human hyaline cartilage. Eur Cell Mater. 2005;9:58-67.

16. Kuzkaya N, Weissmann N, Harrison D, Dikalov S. Interactions of peroxynitrite, tetrahydrobiopterin, ascorbic acid, and thiols: implications for uncoupling endothelial nitric-oxide synthase. J Biol Chem. 2003;278:22546-54.

17. Hafizah AH, Zaiton Z, Zulkhairi A, Mohd Ilham A, Nor Anita MMN, Zaleha AM. Piper sarmentosum as an antioxidant on oxidative stress in human umbilical vein endothelial cells induced by hydrogen peroxide. J Zhejiang Univ-Sc B. 2010;in press.

18. Drummond G, Cai H, Davis M, Ramasamy S, Harrison D. Transcriptional and posttranscriptional regulation of endothelial nitric oxide synthase expression by hydrogen peroxide. Circ Res. 2000;86:347-54.

19. Thomas S, Chen K, Keaney J. Hydrogen peroxide activates endothelial nitric-oxide synthase through coordinated phosphorylation and dephosphorylation via a phosphoinositide 3-kinase-dependent signaling pathway. J Biol Chem. 2002;277:6017-24.

20. Landim M, Casella Filho A, Chagas A. Asymmetric dimethylarginine (ADMA) and endothelial dysfunction: implications for atherogenesis. Clinics. 2009;64:471-8.

21. Ignarro L, Byrns R, Sumi D, de Nigris F, Napoli C. Pomegranate juice protects nitric oxide against oxidative destruction and enhances the biological actions of nitric oxide. Nitric Oxide. 2006;15:93-102.

22. Miean K, Mohamed S. Flavonoid (myricetin, quercetin, kaempferol, luteolin, and apigenin) content of edible tropical plants. J Agric Food Chem. 2001;49:3106-12.

23. Kuhlmann C, Schaefer C, Kosok C, Abdallah Y, Walther S, Lüdders D, et al. Quercetin-Induced Induction of the NO/cGMP Pathway Depends on $\mathrm{Ca}$ 2-Activated $\mathrm{K}$ Channel-Induced Hyperpolarization-Mediated Ca 2+-Entry into Cultured Human Endothelial Cells. Planta Med. 2005;71:520-4.

24. Taubert D, Berkels R, Klaus W, Roesen R. Nitric oxide formation and corresponding relaxation of porcine coronary arteries induced by plant phenols: essential structural features. J Cardiovasc Pharm. 2002;40:70113. 